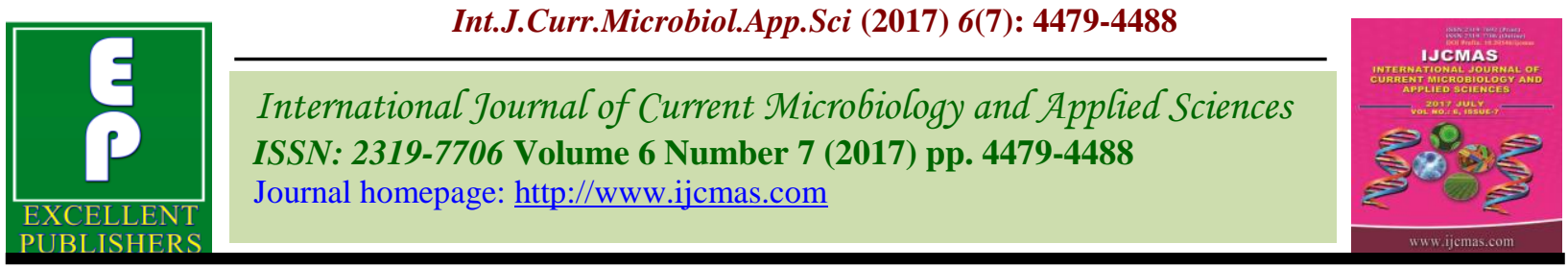

Original Research Article

https://doi.org/10.20546/ijcmas.2017.607.467

\title{
Development of Kantha Embroidery Motifs to Designs: Traditional to Contemporary
}

\author{
Saroj Devi*, Parveen Punia, Neelam Pruthi and Nidhi Sisodia
}

Department of Clothing and Textile, I.C. CCSHAU, Hisar 125004, Haryana, India

*Corresponding author

\section{A B S T R A C T}

\begin{abstract}
Keywords
Kantha embroidery, Motifs, Designs.

Article Info

Accepted:

30 June 2017

Available Online:

10 July 2017 evaluation and variety in shape and presentation. In designing, a weaver, embroider, dyer or printer creates dreams of beauty using motifs familiar through culture, religion, environment and history on textiles. Development in any field is essential and continuing process so in the field of traditional textiles. The information was gathered from thirty shops for contemporary use of motifs, categories of motifs and other techniques adapted for traditional embroideries. The maximum no. of floral motifs of Chikankari, Phulkari, Kashida \& Kathiawar embroidery were in contemporary use which were mainly worked in machine embroidery except the Kantha embroidery. Out of collected embroideries through market survey, one embroidery that is Kantha was selected. Fifty motifs of selected embroidery were collected from primary and secondary sources. Out of these, fifteen motifs were selected to develop stylized designs for jacket. Fifteen stylized designs were developed and five possible placements of each design were prepared with the help of coral draw.
\end{abstract}

Motifs play an important role in designing. Each motif, like the fabric itself has an origin,

\section{Introduction}

Each region and country has its own distinctive style of embroidery, which incorporates the culture, their history and tradition. Kantha embroidery involves a simple running stitch. It is the way the embroidery has been used that makes it extra ordinary. It is a typical example of how a simple stitch can create elaborate motifs. Usually the motifs are gods and goddesses, animals like duck, fish, peacock; floral \& geometric patterns (Anonymous, 2009). Kantha embroidery is classified into Lepkantha and Sujni Kantha depending on the use of the finished products in the art. The embroidery basically involves outlining decorative motifs with running stitch, using colourful threads. There are several patterns that can be used to cover the entire cloth. Kantha embroidery involves a simple running stitch. It is the way the embroidery has been used that makes it extra ordinary. It is a typical example of how a simple stitch can create elaborate motifs. Usually the motifs are gods and goddesses, animals like duck fish peacock; floral \& geometric patterns that mean it can be anything the worker can relate to. It was highlighted by household articles and other textile products can be developed utilizing the developed designs by using weaving techniques or the developed designs can be applied on the surface of the textile by painting, embroidery or printing or distinct 
ranges of textiles could be created using combination (Sangama et al., 2012).

Use of traditional embroidery designs for transformation into fabric painting will help in the revival of traditional embroidery \& give it a new look as per trends. Motifs and designs are weaved or embodied following certain indigenous techniques (Teron et al., 2012).The information was collected by the administering the formulated interview scheduled, informal discussion cum observation to selected samples of 50 namda workers including the 5 case study samples (Karolia et al., 2014)

\section{Materials and Methods}

An exploratory work was undertaken to gather information regarding motifs of Indian embroideries transformed into other techniques for contemporary use. Clothing and household articles were scanned for collection of motifs. Twenty Five Shops dealing in clothing items, household linens including bed linen, bed covers, table covers and other household articles, four boutiques and a mall of Hisar market were explored through personal interview method.

A research work adopted unstructured interview and personal observations to find status of traditional knowledge on weaving and to find out the intrinsic relationships between biological objects and cultural artifacts during 2002-2008 among the Karbis (Teron et al., 2012). Five motifs i.e. one from each embroidery, able to be transformed into fabric painting were selected. Selected motifs were analyzed through comparative study for selecting one of those traditional embroideries, which was giving best effect for fabric painting, for further study. Kantha embroidery was selected for collection of motifs and design development. Fifty motifs of Kantha embroidery were collected from primary source keeping in mind their suitability for fabric painting and jacket for woman. Out of fifty motifs, fifteen suitable motifs were selected and fifteen stylized designs were developed from them using Coral Draw. Five placements of each design were made on Jacket with the help of coral draw. Designs and their placements on the Jacket were selected on the basis of most preference using Weighted Mean Scores rank method.

A preferential choice index for selection of design and their placements was developed. The experts were asked to give their preferences on three point scales for developed design \& their placements. The faculty members \& Ph.D. student of Department of Textile and Apparel Designing of Home Science were taken as experts. Ranks were given on the basis of Weighted Mean Scores. Three top ranked designs \& one placement of each of top ranked design were selected for preparation of jackets. These placements were used for product development.

For product development most frequently occurred bust jacket size, 34 inch, was selected. Selected bust size jackets were drafted and cut using standardized measurements (Kumari et al., 1991). Selected designs were traced on the cut piece of jackets as per their selected placements. Three jackets were developed using embroidery technique and another three jackets were developed using painting technique.

A total of six jackets were developed. Developed design and jackets were assessed on the basis of acceptability using mental readiness of the experts. A modified preferential index was developed and suitable design and jackets were selected using Weighted Mean Scores ranking methods. 


\section{Results and Discussion}

Information regarding motifs of Indian embroideries transformed into other techniques for contemporary use

The information regarding motifs of Indian embroideries in contemporary use and their transformation into other techniques was gathered from Hisar market has been presented in the sections. The motifs of traditional Indian embroideries found in contemporary use were categories according to the Classification given in book by Naiak and wilson (2006). It was found that the maximum no. of motifs of Kantha embroidery was used for contemporary use i.e. $26 \%$ in the local market of Hisar city. This was closely followed by Chikankari \& Phulkari motifs. The contemporary use of Kutch \& Kasuti motifs was less.

\section{Traditional Indian embroidery motifs found in contemporary use}

The data in figure 1 revealed that the maximum number of motifs $\left(26 \%\right.$ with $1^{\text {st }}$ rank) of Kantha embroidery were in contemporary use in the local market of Hisar city. This was closely followed by Chikankari \& Phulkari motifs (20\% \& 18\%). The contemporary use of Kutch \& Kasuti motifs was less i.e. $6 \%$ each.

Similarly, Jani and Khosla (2000) has expressed that Kantha embroidery has a history of about 300 yrs old. This craft is gaining popularity in India and abroad because of its immaculate stitching designs on variety of items like sarees, dress materials, shawls and bed covers. The materials of Kantha were rags and their threads were joined together, which gave a new wholeness. The main fabrics used were cotton and tussar silk and embroidery was done with colourful cotton threads. Different Kantha stitches were
Pechni, Murri and Phanda. Further the contemporary Kantha embroidery is not limited to multi-layered saris or dhotis. Today, it is seen on the beautiful garments, like sarees, dupattas and ethnic wears for men and women, apart from bed linen and cushions. The best fabrics used for Kantha stitch are cotton and silk (Anonymous, 2011).

Contemporary use of floral motifs of traditional embroidery was found on top followed by animal \& birds. The use of human \& ethnic motifs was less. Gangotra (1998) reported in her study that embroidery was being done on articles of apparel used by both males and females. Various numbers of stitches were being used to embroider the apparels. The common motifs being embroidered were floral and birds.

Maximum no. of Indian embroidery motifs were found to be worked in machine embroidery i.e. $54 \%$ \& this was followed by hand embroidery including ari work \& printing. Painting was rarely observed in the market to work the Indian embroidery motifs.

Categories of Indian embroidery motifs found in contemporary use

The data presented in figure 2 revealed the categories of the motifs found in contemporary use. The use of floral motifs of traditional embroidery was found on top i.e. $60 \%$ followed by animal \& birds category i.e. $18 \%$. The human \& ethnic motifs was used only $16 \%$.

\section{Multiple Responses}

\section{Traditional Motifs Worked With Different Techniques}

Data in table 1 depicts the different techniques used to work Indian embroidery motifs for contemporary use. Maximum 
number of Indian embroidery motifs were found to be worked in machine embroidery i.e. $54 \%$, followed by hand embroidery including ari work i.e.42\% and printing i.e. $36 \%$. Painting was rarely observed in the market for use of embroidery motifs.

\section{Selection of Kantha embroidery motifs}

Motifs which were embroidery found suitable for adaptation into fabric painting as well as jacket were finalized for design development.

Selected Motifs of Kantha Embroidery

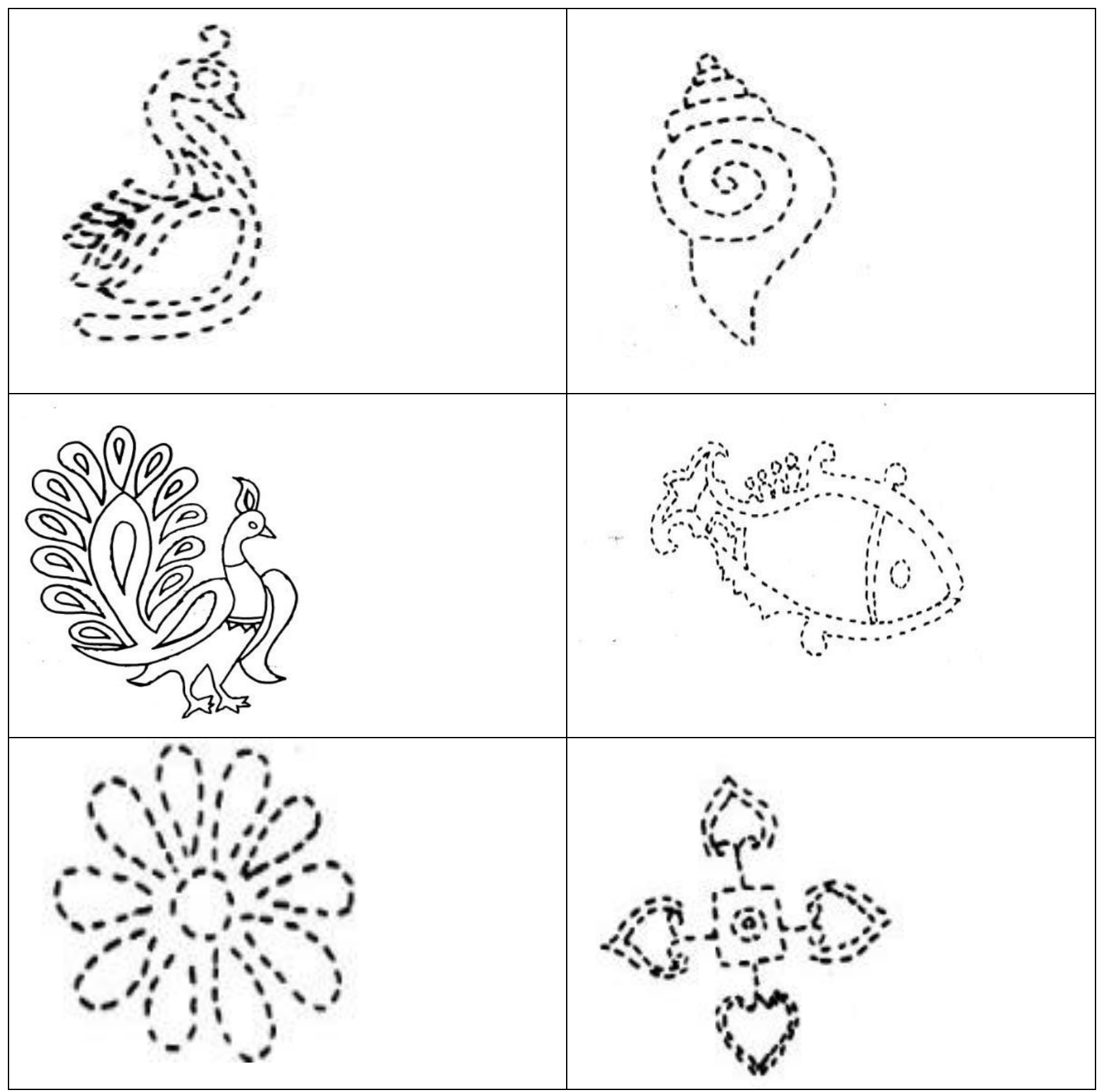




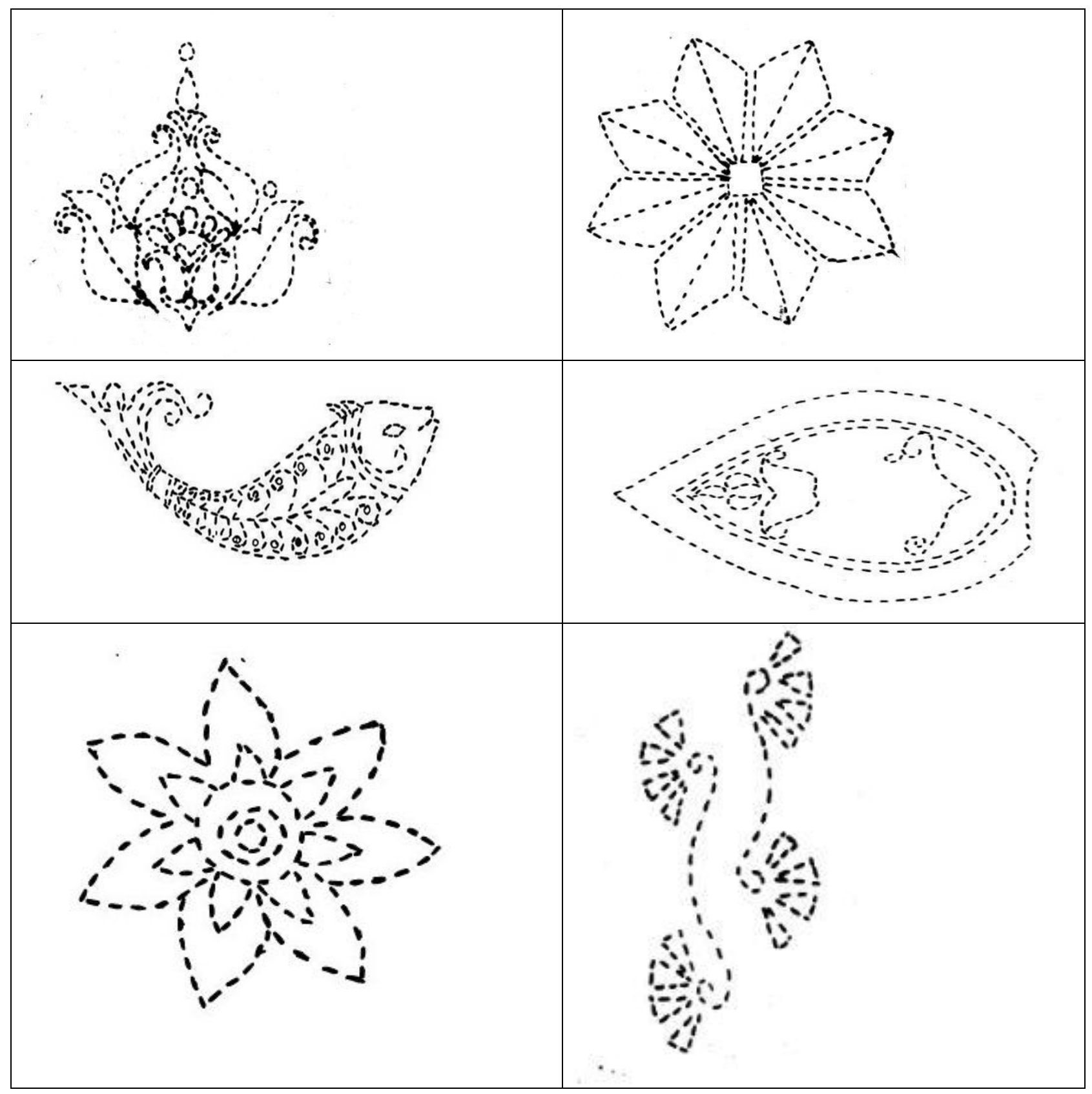




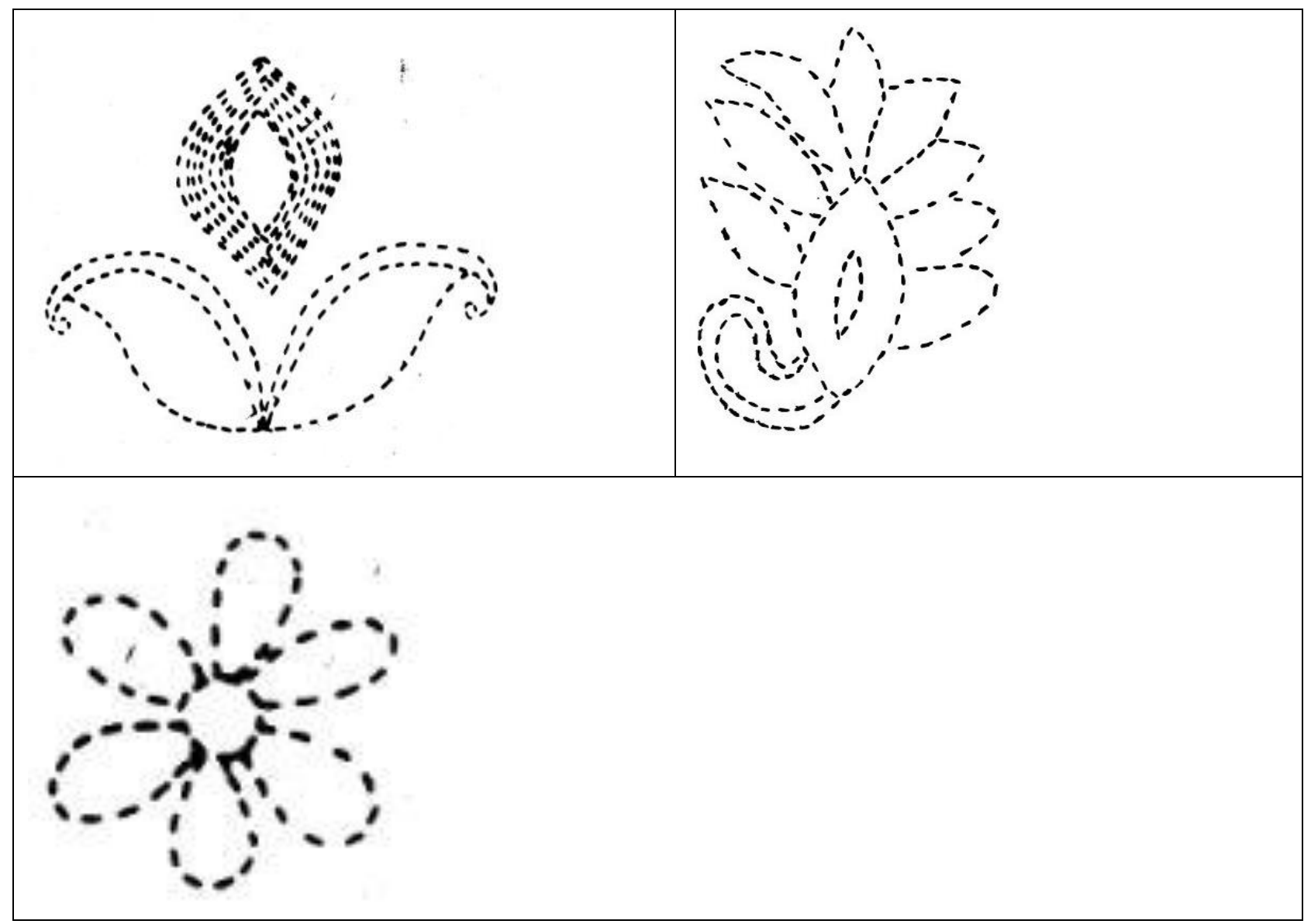

Table.1 Traditional motifs worked with different techniques $\mathrm{N}=50 *$

\begin{tabular}{llcc}
\hline S. No. & Techniques & Freq. (\%) & Rank \\
\hline 1) & Hand embroidery & $23(42)$ & II \\
2) & Machine embroidery & $27(54)$ & I \\
$3)$ & Printing & $18(36)$ & III \\
$4)$ & Painting & $3(6)$ & IV \\
\hline
\end{tabular}

Figure in parenthesis indicate percentage

Table.2 Experts' preferences for developed designs ( $\mathrm{N}=20)$

\begin{tabular}{cccc}
\hline S. No. & Design no. & WMS & Ranks Order \\
\hline 1 & & 2.55 & V \\
& & & \\
& & & \\
\hline
\end{tabular}




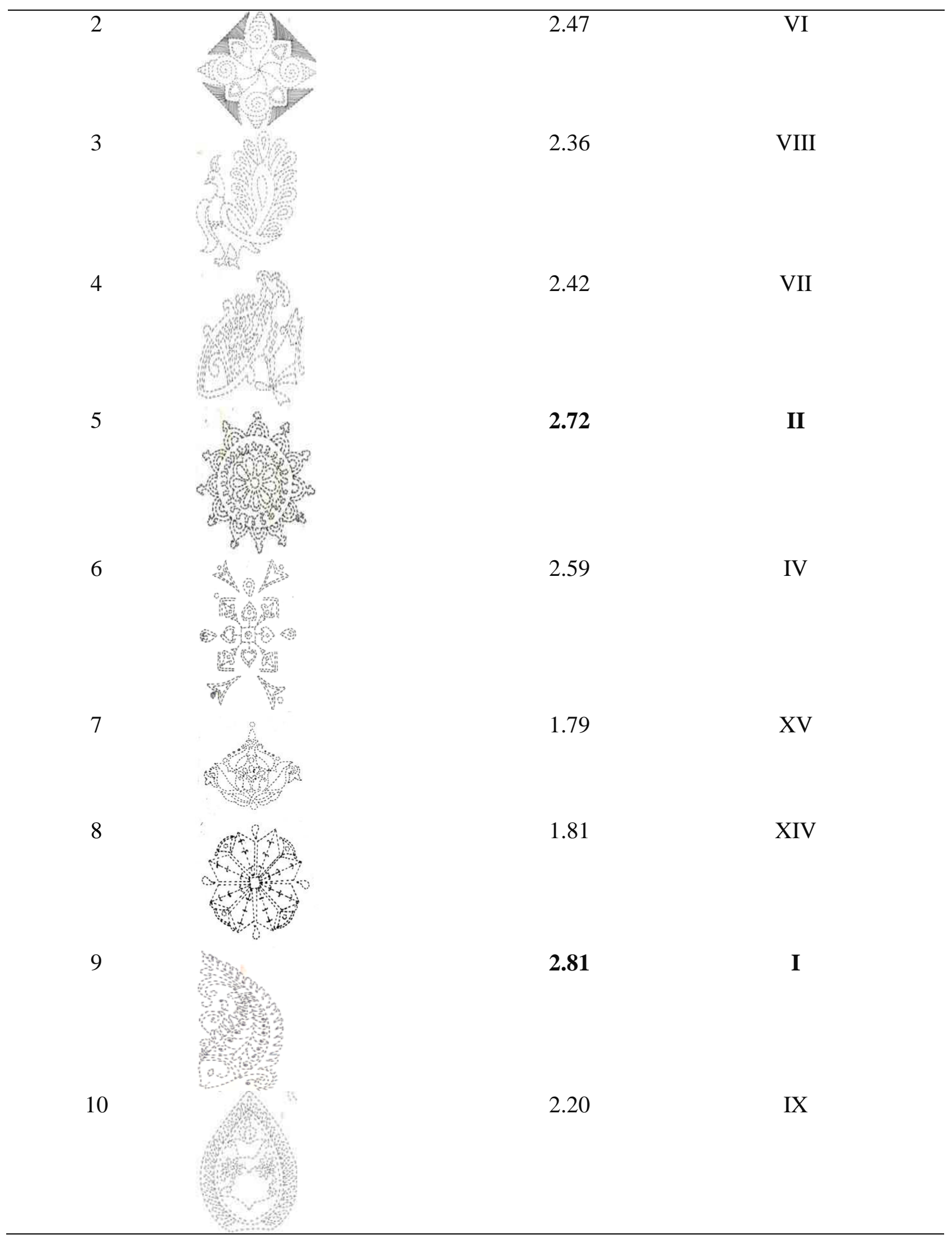




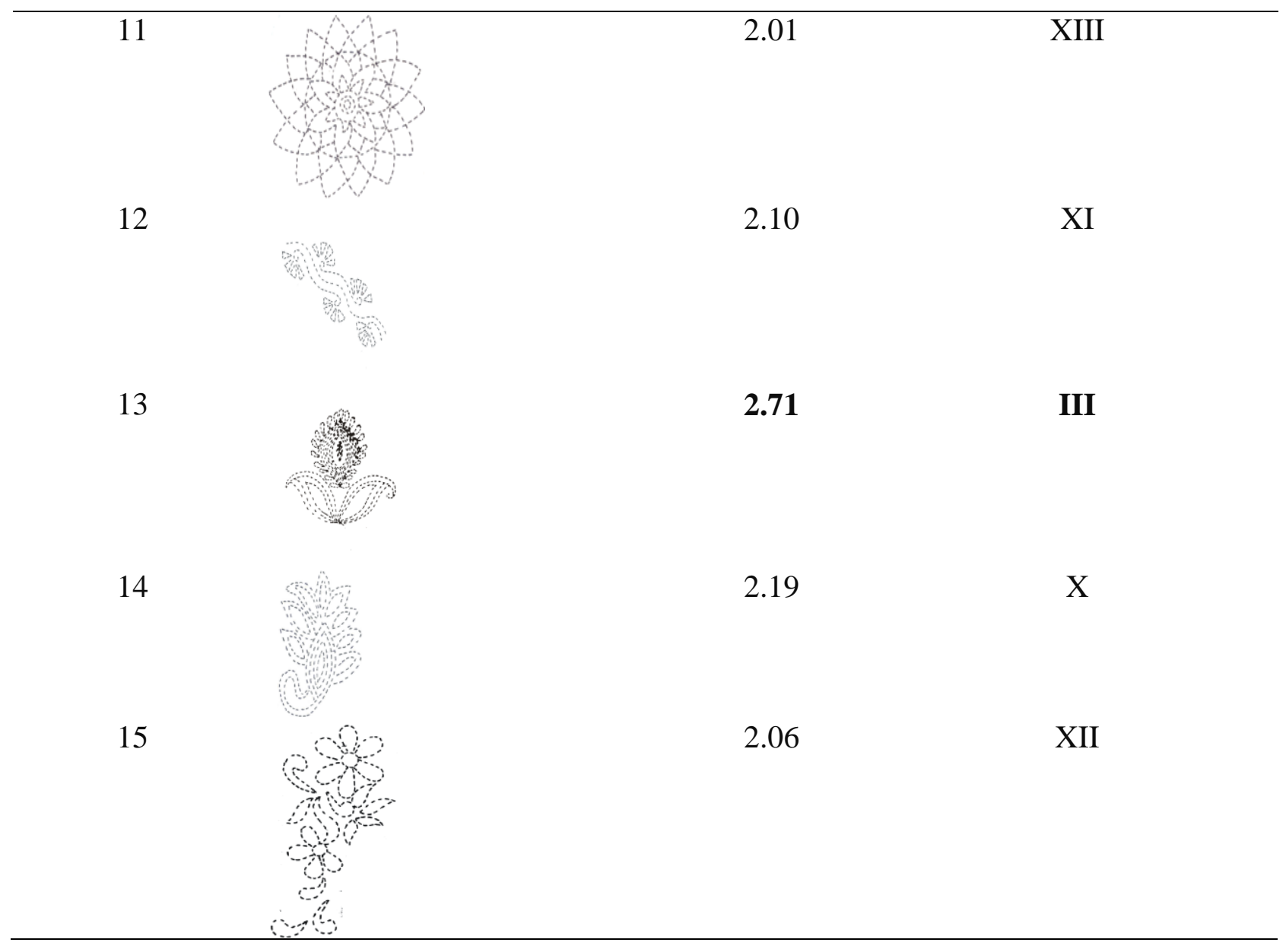

Table.3 Assessment of the developed articles as per appeal level of the developed design and overall appearance $(\mathrm{N}=20)$

\begin{tabular}{lcccc}
\hline \multirow{2}{*}{ Jacket (Embroidery) } & \multicolumn{2}{c}{ Developed design } & \multicolumn{2}{c}{ Overall appearance } \\
\cline { 2 - 5 } & WMS & Ranks & WMS & Ranks \\
\hline Design no.9 & 2.67 & I & 2.76 & I \\
Design no.13 & 2.20 & II & 2.37 & II \\
Design no.5 & 1.90 & III & 2.05 & III \\
\hline Jacket (Painting) & & & & \\
Design no.9 & 2.67 & I & 2.96 & I \\
Design no.13 & 2.20 & II & 2.63 & II \\
Design no.5 & 1.90 & III & 2.49 & III \\
\hline
\end{tabular}

WMS-Weighted Mean Score 

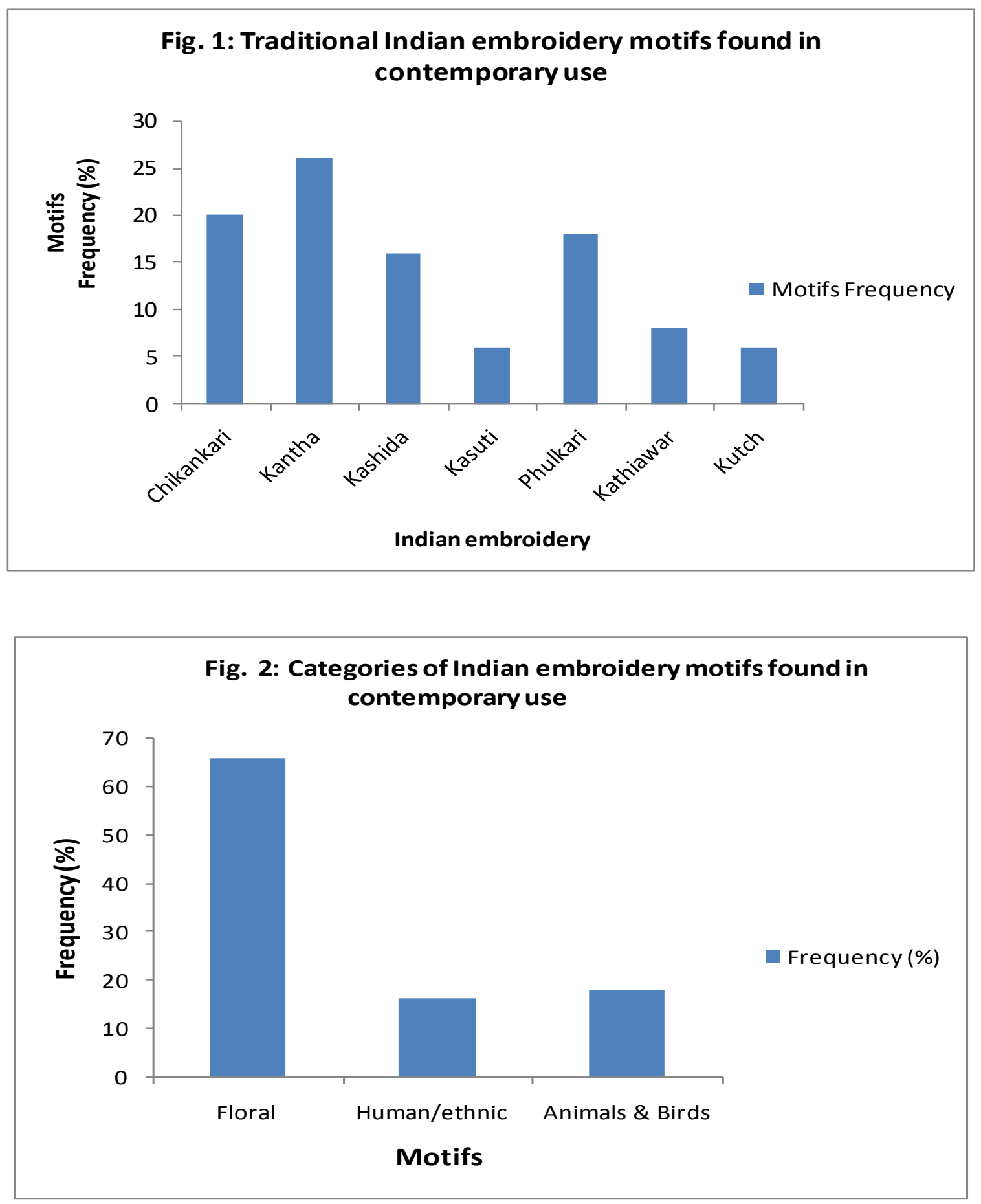
Fig.3 Selected traditional embroidery designs for adaptation into fabric painting according to preference

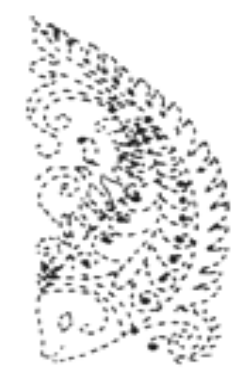

Design no.9 (First)

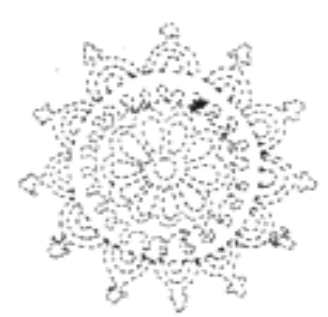

Design no.5 (Second)

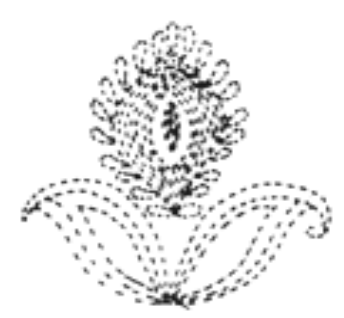

Design no.13 (Third)

\section{Experts' preferences for developed designs}

All the fifteen developed designs are presented in table 2 . revealed that design number 9 (2.81) was most preferred by experts followed by design no.5 (2.72) and design no 13 (2.71) The other designs in descending order were 6 (2.59), design no. 1 (2.55), design no.2 (2.47), design no. 4 (2.42), design no.3 (2.36), design no. 10 (2.20), design no.14 (2.19), design no.12 (2.10), design no.15 (2.06), design no. 11 (2.01) \& design no. 8 (1.81). The least preferred design was 7 (1.79) (Fig. 3).

\section{References}

Anonymous. 2009. http://www. bharatonline. com/west-bengal/arts-and-crafts/kanthaembroidery.html retrieved on august. 13, 2009.

Anonymous. 2011. Kantha-embroidery, www. bharatonline.com/westbengal/arts-and-crafts/kanthaembroidery.html.

Gangotra. 1998. Sanskriti Evem Kala (Hindi).
Haryana Sahitya Acadami, Panchkula, 147-152.

Jani, A. and Khosla, S. 2000. Timeless elegance of Indian Embroidery, A Special Supplement to Express Textile, pp. 28-34.

Karolia, A. \& Sardiwal, S. 2014. Namda- the traditional felted craft of Rajasthan. Indian J. Traditional Knowledge, 13(2): 409-415.

Kumari, V. 1991. Changing trends in costumes of bishnoi community, MSc Thesis, (CCS HAU, Hisar, India).

Naiak, S.D. and Wilson, J.A. 2006. Surface Designing of Textile Fabrics, New Age International (Pvt) Publishers New Delhi, pp. 15-17.

Sangama, E.M. and Rani, A. 2012. Development of designs for textile designing. Text. Trends, 54(3): 29-34.

Teron, R. \& Bortakur. 2012. Biological motify and designs on traditional costumes among Karbis of Assam. Indian J. Traditional Knowledge, 11(2): 305-308.

\section{How to cite this article:}

Saroj Devi, Parveen Punia, Neelam Pruthi and Nidhi Sisodia. 2017. Development of Kantha Embroidery Motifs to Designs: Traditional to Contemporary. Int.J.Curr.Microbiol.App.Sci. 6(7): 4479-4488. doi: https://doi.org/10.20546/ijcmas.2017.607.467 